\title{
Aus den Berliner Gesellschaften. Sitzung-der Ophthalmologischen Gesellschaft vom 27. Juni 1901
}

Herr Mendel demonstriert eine Zeiclmung Yon ringförmiger Netzh au tab lösung.

Herr Fehr spricht über bandförmige Hornhauttrübung und weist auf deren Zusammenhang mit Gicht bin.

Herr Lehniann berichtet iiber einen Fall von doppelseitiger acuter Neuritis retrobulbaris bei einem 48jährigen Mann, der seit einem Jahr an Carcinoma ventriculi litt. Andere Intoxicationen fehlten. S. beiders. =, fast völlige Amaurose, Papillen verwaschen. Melirere Monate später (nach Aufnahme ins Krankenhaus) $S=2 / 3-1$ ! Die Sektion erfolgte 48 Std. p. m. Die Optici wurden in Seriensclmitte zerlegt und nach $\Lambda$ Veigert gefärbt; ob der Prozess im Interstitium (Uhthoff) oder in den NerYenfasern beginnt, lässt Vortr. unentschieden. In der Litteratur sind nur 3 derartige Fälle bei Carcinom beschrieben. Das Re'sumé von L.'s Ausführungen gipfelt darin, dass der Prozess auf einer Autointoxication (Ptomaine) beruht, wie auch Remak die Polyneuritis auf solche zurückíuhrt.

Herr Hirschberg meint, dass der anatomische Prozess wohl dicht hinter dem Bulbus beginne, und berichtet von einem juiigen Mädchen, das 10 Tage lang Amaurose aufwies, dann wieder gute S. erlangte. Was den typischen opbthalmoscop. Befund betrifft, so ist der-selbe im Anfang normal. Später bleibt eine leichte Abblassung selbst bei Wiederherstellung der S. zurück.

Herr Steindorff spricht tiber zweí Fälle von Glaskörper-abscess nach Verletzung, bei welchen Bacterien nicht gefunden wurden.

Herr Mendel berichtet über 1645 Starextractionen, die von 1869-1901 von Prof. Hirschberg gemacht wurden, mit Bezug auf die früher kultivierte Reclination.

$12^{*}$

176 Sitzungsboriohte, Tagesnachrichten und Notizen.

Unter den 1645 Fallen waren 36 alter als 80 Jahre; von diesen

trat ein nial Glaskörperverlust und ein Exitus letalis ein. Die

Reclination ist unangebracht, da sie $50 \quad$ pCt. Verlust bei Hochbetagten

ergiebt. Pollack.

Sitzung · des Vereins für innere Medicin

vom 1. Juli 1901.

Heı $\tau$ Litten: Ueber retinale Affectionen bei inneren Erkrankungen.

Schon 1876 hat Litten über Veränderungen im Fundus bei Septicämie berichtet, indem von 35

Fallen mit letalem Ausgang sicli 28 mal die Befunde zeigten. Meist traten die Affectionen kurz vor dem Tode auf, dergestalt, dass sich weisse Flecke von verscliiedener Gestalt, dicht neben der Papule, menials in der Macula lutea, neben Blutungen einstellten, und zwar entwickelten sie sich rapide. Acht mal handelte es sich dabei um metastat. Ophthalmie. Das Resultat jener Untersuchungen ergab also damals: $1.80 \mathrm{pCt}$. Veränderungen, 2. stets Exitus, 3. rapiden Veiiauf. - Herrnheiser fand nun nur $30 \mathrm{pCt}$. Veränderungen, Litten neuerdings auch nur $30 \mathrm{pCt}$; ; ebenso trat nicht immer der Tod ein, selbst bei einem Verlauf von sechs Monaten. Wenn aber nun die 
Prognose nicht eine absolut schlechte ist, so behält L. doch in diagnostischer Hinsicht seinen früheren Stand-punkt bei. Ausser bei der Septicämie finden sich diese Veränderungen noch bei Morb. Brighti, bei Diabetes, Scorbut, bei perniciöser Anämie und Leukämie.

Die histologischen Veränderungen sind nun sehr interessant (nach den Befunden an neun Augen von pernic. Anämie, Septicämie und Leukämie). Die weissen Herde finden sich immer in der Nerven-faserschicht, dicht neben der Papille, sie stellen rundliche Einbettungen dar, ohne in andere retinale Schichten einzudringen. Eine bestimmte Structur lassen sie nicht erkennen. Litten meint, dass es sich um ein schnell gerinnendes Exsudat handele, wofür auch die völlige Resorption spricht; fälschlicL·er $\Lambda$ Veise deutete man früher diese Ilerde als varicose Nervenfasern. Auch um eine Embolie handelt es sich nicht, da die Gefässe stets normal gefunden werden. Eine Erklärung dafür, warum diese Herde bei so verschiedenen Prozessen auftreten, hat L. noch nicht gefunden. Die diagnostische Bedeutung der Flecke liegt darin, dass bei Typhus Fundusveränderungen nicht be-kannt sind, in dubio man sich also dann für Septicämie entscheiden muss; bei tubercul. Meningitis und acut. Miliartuberculose kommen nur die Blutungen vor, bei Meningitis zeigt sich ferner noch Papillitis, die von Litten bei der Septicämie nicht beobachtet worden ist.

Pollack.

Tagesnachrichten und Notizen.

Prof.D. Dr. Manz in Freiburg ist in den Ruhestand getroten.

Primararzt und Docent Dr. Julius von Siklóssi in Budapest ist 63 Jahre alt gestorben. 